\title{
Wat doet supervisieonderwijs bij huisartsen in opleiding? Resultaten van een onderzoek naar effectbeleving onder HAIO's aan de huisartsopleiding van het VUMC
}

\author{
G. Locher, A.H. Blankenstein
}

\section{Samenvatting}

Inleiding: Supervisieonderwijs wordt gegeven aan derdejaars huisartsen in opleiding (HAIO's) en betreft onderwijs waarin drie HAIO's met een supervisor ervaringen in praktijk en leren bespreken. Doel van het supervisieonderwijs is beter te leren reflecteren, het zelfinzicht te vergroten, daaruit consequenties te trekken en het eigen leerproces meer zelf te sturen. De vraag bij de evaluatie was: "Wat ervaren de HAIO's als de sterkste en zwakste effecten van dit onderwijs?"

Methoden: Een in 1998 opgestelde enquête bevat uitspraken over mogelijke effecten. HAIO's uit de groepen die in 1999-2001 supervisie hadden gelopen $(n=108)$ konden antwoorden op een 5-punts schaal lopend van zeer mee oneens tot geheel mee eens. De sterkte werd als volgt berekend: de extreme negatieve en positieve scores (1 en 5) werd score 2 gegeven, de niet extreme scores (2 en 4) werd score 1 gegeven en de middenscore (3) werd score 0 gegeven.

Resultaten: Van 54 HAIO's (respons 50\%) werden formulieren ontvangen. Als sterkste effecten werden ervaren: het meer experimenteren met het eigen gedrag en het meer aandacht besteden aan hoe men met zichzelf omgaat. Een grotere geïnteresseerdheid in de opvattingen van de HAIO en het minder moeite hebben met het op tijd afronden van de eigen consulten en met de eigen neiging om patiënten te veroordelen werden als de zwakste effecten ervaren. Discussie: De resultaten suggereren dat bewustwording van specifieke eigen kenmerken bereikt wordt, maar acceptatie van wat de HAIO's zich bewust worden niet. De auteurs pleiten voor acceptatie als expliciete doelstelling voor het supervisieonderwijs. Nieuwe invalshoeken voor het formuleren van effectitems worden voorgesteld. (Locher $G$, Blankenstein AH. Wat doet supervisieonderwijs bij huisartsen in opleiding? Resultaten van een onderzoek naar effectbeleving onder HAIO's aan de huisartsopleiding van het VUMC. Tijdschrift voor Medisch Onderwijs 2004;23(3):143-152.)

\section{Inleiding}

Sinds een aantal jaren is supervisieonderwijs een verplicht onderdeel in het derde blok van de huisartsopleiding van de Vrije Universiteit. Supervisieonderwijs wordt gegeven aan groepjes van drie derdejaars huisartsen in opleiding (HAIO's), die eens per twee weken samenkomen onder leiding van een vaste supervisor. De supervisor kan een in supervisie geschoold staflid zijn of een ervaren supervisor van buiten de opleiding. De doelen die in dit onderwijs worden nagestreefd zijn: ${ }^{1}$
1. Beter leren reflecteren.

2. Vergroting van zelfinzicht (bewustwording).

3. Gemakkelijker consequenties leren trekken uit eigen mogelijkheden en beperkingen.

4. Meer sturing leren geven aan het eigen leerproces.

Deze doelen komen in grote lijnen overeen met de doelen die ook in het supervisieonderwijs aan de huisartsopleiding in Nijmegen gelden. ${ }^{2}$ Evenals in Nijmegen is supervisie als leermethode onder andere 
gebaseerd op het ervaringsleren, zoals beschreven door Kolb in de leercirkel: reflectie, begripsvorming, het maken van een plan en het toepassen van het plan in de praktijk. ${ }^{3}$

Om na te gaan hoe deze arbeidsintensieve methode gewaardeerd wordt door de HAIO's aan de Vrije Universiteit, hebben wij in 1998 een evaluatievragenlijst opgezet. Deze lijst is voor wat betreft de procesevaluatie gebaseerd op een lijst die in Nijmegen is geconstrueerd en afgenomen bij de HAIO's aldaar. ${ }^{4}$

Effectevaluatie betreft de vraag of de beoogde doelen van supervisieonderwijs worden gehaald en daarnaast of er meer effecten optreden, gewenst of ongewenst. Dat betekent dat de doelen, die geformuleerd zijn voor supervisieonderwijs, niet alleen bepalend zijn voor de te meten effecten. Daarnaast zijn de hierboven geformuleerde vier doelen niet eenduidig te vertalen in voor de HAIO voelbare, concrete effecten. We hebben dan ook een vragenlijst ontwikkeld die min of meer is afgeleid uit de doelstellingen en daarnaast ook mogelijke voelbare effecten geformuleerd op basis van eigen ervaringen als supervisant (degene, die supervisie ontvangt) en supervisor. Nadat we die vragen hebben voorgelegd aan een aantal personen die supervisie geven, met de vraag wat zij er aan toe te voegen hebben, c.q. wat zij onzin vonden, ontstond een lijst van potentiële effecten, die in de volgende categorieën ingedeeld werden:

1. Hoe de supervisant omgaat met de oorzaken van probleemsituaties: is daar meer 'beweging in gekomen'?

2. Hoe de supervisant omgaat met de spanning tussen het voldoen aan wensen vanuit de omgeving (patiënten, opleider, praktijkroutines) enerzijds en de eigen normen anderzijds, waarbij er vanuit gegaan is dat de angst niet geaccepteerd te worden in deze spanning een grote rol speelt. De vraag hierbij is of de spanning minder is geworden tijdens de supervisie.

3. Hoe de supervisant omgaat met zichzelf: is haar of zijn be- of veroordeling van zichzelf scherper of milder geworden, hoe gaat het met het zelfvertrouwen?

4. Hoe de supervisant omgaat met diens omgeving: is zijn of haar interesse in de omgeving toegenomen, is de be- of veroordeling van anderen of van het gedrag van anderen milder of juist scherper geworden.

De vragen die ten grondslag liggen aan de effectevaluatie zijn: op welke gebieden hebben de grootste en de geringste veranderingen plaats gevonden en geven die veranderingen aanwijzingen voor een onderliggende structuur in de mogelijke effecten, waardoor het inzicht in wat er eigenlijk gebeurt tijdens de supervisie wordt vergroot? In onderstaand artikel geven wij een overzicht van de antwoorden van 54 HAIO's die supervisie hebben gevolgd in de periode van 1999 tot en met 2001.

\section{Methoden}

De evaluatievragenlijsten die werden voorgelegd aan HAIO's die hun supervisieonderwijs hadden afgesloten, werden gedurende drie jaren ingezameld (19992001). De vragen naar het effect van supervisie zijn geformuleerd in stellingen, waarop de respondent kon aangeven of hij of zij het er geheel mee oneens (score 1) of geheel mee eens (score 5) was.

Om vast te stellen op welke vragen de grootste veranderingen zichtbaar zijn, is uitgegaan van de vooronderstelling dat het percentage HAIO's dat scoort op de middencategorie (noch eens, noch oneens) een indicatie is voor het percentage 
HAIO's dat op die stelling geen verandering heeft doorgemaakt. Anderzijds: hoe hoger het percentage op de extreme kanten van het item, hoe sterker de veranderingen op dit item. Op deze wijze is er voor elk item een score berekend, waarbij de score 3 een 0 is voor verandering, score 2 of 4 een 1 en score 1 of 5 een 2 weergeeft voor de verandering. Zoals uit de vraagstelling geconcludeerd kan worden, gaat het niet om verandering in een bepaalde richting. Bij HAIO's, bijvoorbeeld, die zichzelf scherp be- of veroordelen en zichzelf daarmee dwarszitten, is een verandering in de richting van mildere beoordeling een gunstige. Omgekeerd mogen HAIO's die te weinig kritisch zijn best veranderen in de richting van een scherpere be- of veroordeling van zichzelf. Het gemiddelde per item geeft dan aan in welke mate de HAIO's extreem hebben gescoord en - als de aanname klopt - veranderd zijn tijdens de supervisie.

\section{Resultaten}

\section{Respons}

In de onderzoeksperiode zijn 108 HAIO's in de gelegenheid geweest om supervisieonderwijs te volgen. Uiteindelijk zijn er 54 ingevulde enquêteformulieren terug ontvangen, hetgeen $50 \%$ is. Vermoedelijk is het responspercentage relatief laag, omdat er nogal wat HAIO's wegens zwangerschappen of om andere redenen hun reguliere supervisieonderwijs niet konden afmaken en daardoor voor deze enquête uitvielen. Daarnaast zijn er ook een aantal enquêteformulieren niet ingevuld, omdat de supervisie voor een deel 'buitenshuis' werd gehouden en de voorziening van enquêteformulieren of het innemen ervan soms niet lukte.
Door HAIO's gerapporteerde effecten van supervisie

In tabel 1 wordt weergegeven welke veranderingen de HAIO's rapporteren als gevolg van supervisie. Wat betreft het toekennen van een oorzaak voor probleemsituaties valt op dat de beweging tijdens de supervisie vooral is in de richting van het oorzaken meer binnen zichzelf zoeken (eigen karakter of eigen gedragspatroon). Wel gaat een niet onaanzienlijk percentage de oorzaak van problemen (ook?) meer buiten zichzelf zoeken, namelijk in de situatie. Bij ongeveer een derde van de respondenten is op dit gebied geen beweging te zien.

Op de schaalitems die betrekking hadden op een verandering in de spanning tussen het voldoen aan de normen, verwachtingen van de buitenwereld enerzijds en hun eigen normen anderzijds, komt er een overduidelijke verschuiving naar rechts uit, het sterkst bij het item 'grenzen stellen'.

Op de uitspraken die betrekking hadden op het omgaan met commentaar en kritiek treedt vaak verandering naar rechts op, het meest uitgesproken bij stelling 8: 'Ik handel minder vanuit het gevoel dat ik persoonlijk aangevallen word'. Ook wat betreft het omgaan met zichzelf als persoon is er sprake van een verschuiving naar rechts, naar de kant waarbij men tijdens de supervisie minder moeite krijgt met het omgaan met verschillende facetten van zichzelf. Alleen stelling 15, over het starten van een hobby, geeft een verschuiving naar links te zien.

In de rubriek 'Omgaan met de omgeving' treedt ook verschuiving naar rechts op. Wel scoort hier een groot percentage in het midden. Dit wil zeggen dat er bij veel HAIO's op dit gebied vermoedelijk weinig is gebeurd. De sterkste rechtsverschuiving treedt op bij stelling 16: 'Ik ex- 
Tabel 1. Zelfgerapporteerde effecten van supervisie.

\begin{tabular}{lllllllll} 
N1 & & \multicolumn{2}{c}{ Score in $\%^{2}$} & \multicolumn{2}{c}{$\begin{array}{c}\text { Veranderings- } \\
\text { score }^{3}\end{array}$} \\
\hline & 1 & 2 & 3 & 4 & 5 & Gem. & (SD)
\end{tabular}

Omgaan met oorzaken van probleemsituaties

1. Ik wijs de situatie en/of anderen in de situatie meer als

$\begin{array}{lrrrrrrr}54 & 11 & 33 & 28 & 24 & 4 & 0,87 \\ 54 & & 15 & 33 & 46 & 6 & 0,72 \\ 54 & & 6 & 34 & 45 & 15 & 0,81\end{array}$
oorzaak aan (leg het probleem meer buiten mijzelf).

2. Ik wijs mijn eigen karakter/persoonlijkheid meer als oorzaak aan (leg het probleem meer binnen mijzelf).

3. Ik wijs mijn gewoontes of mijn gedragspatronen meer als oorzaak aan.

\section{Omgaan met spanning tussen omgevingsnorm en eigen} norm

4. Ik beoordeel en handel meer vanuit mijn eigen normen en waarden.

5. Ik laat mij minder beïnvloeden door het gevoel niet geaccepteerd te worden door de patiënt.

6. Ik laat mij minder beïnvloeden door de wens aardig gevonden te worden.

7. $\mathrm{lk}$ heb minder moeite gekregen met het stellen van mijn grenzen.

\section{Omgaan met commentaar en kritiek}

8. Ik handel minder vanuit het gevoel dat ik persoonlijk aangevallen word.

9. Commentaar op mijn handelen interpreteer ik minder snel als kritiek op mijn persoon.

10. Ik kan meer ontspannen luisteren naar commentaar op mijn handelen.

\begin{tabular}{|c|c|c|c|c|c|c|c|}
\hline 54 & & 4 & 28 & 54 & 15 & 0,87 & $(0,65)$ \\
\hline 52 & & 6 & 46 & 38 & 10 & 0,63 & $(0,66)$ \\
\hline 52 & & 2 & 35 & 54 & 10 & 0,75 & $(0,62)$ \\
\hline 52 & & & 10 & 58 & 33 & 1,23 & $(0,61)$ \\
\hline 51 & 2 & & 41 & 47 & 10 & 0,69 & $(0,65)$ \\
\hline 53 & 6 & 2 & 45 & 34 & 13 & 0,74 & $(0,67)$ \\
\hline 54 & 2 & 7 & 37 & 44 & 9 & 0,54 & $(0,65)$ \\
\hline 52 & 23 & 13 & 56 & 4 & 4 & 0,71 & $(0,87)$ \\
\hline
\end{tabular}

\section{Omgaan met zichzelf als persoon}

11. Ik besteed meer aandacht aan hoe ik met (delen van) mijzelf als persoon (mijn opvattingen, gewoontes, persoonlijkheid e.d.) omga.

12. Ik zie eerder hoe mijn gedrag geduid kan worden als een manier om mij ergens uit te redden.

13. Ik heb minder last van mijn gebrek aan zelfvertrouwen.

14. Ik heb minder moeite met mijn neiging om mijzelf te veroordelen.

15. Ik heb minder moeite gekregen met het feit dat ik geen hobby's meer kon beoefenen: ik ben weer met een hobby begonnen. 


\begin{tabular}{lllllllll} 
N1 & & \multicolumn{2}{c}{ Score in $\%^{2}$} & \multicolumn{2}{c}{$\begin{array}{c}\text { Veranderings- } \\
\text { score }^{3}\end{array}$} \\
\hline & 1 & 2 & 3 & 4 & 5 & Gem. & (SD)
\end{tabular}

Omgaan met de omgeving

16. Ik experimenteer meer met mijn handelen (om daarmee beter met probleemsituaties om te gaan).

17. Ik ben meer gaan experimenteren met mijn gedrag bij patiënten die ik moeilijk vond.

18. Ik heb minder moeite met het feit dat ik patiënten vaak weinig concreets te bieden heb.

19. Ik heb minder moeite met mijn neiging om bepaalde patiënten te veroordelen.

20. Ik zie patiënten meer als uitdaging in plaats van als opgave.

21. $\mathrm{Ik}$ heb minder problemen als er over mijn grenzen is heengelopen.

$\begin{array}{lllllllll}54 & & & 6 & 65 & 30 & 1,24 & (0,55) \\ 54 & 2 & 2 & 11 & 57 & 28 & 1,19 & (0,62) \\ 54 & 2 & 15 & 43 & 31 & 9 & 0,69 & (0,67) \\ 52 & & 4 & 15 & 52 & 30 & 0,52 & (0,57) \\ 54 & & 6 & 16 & 56 & 22 & 1,06 & (0,63) \\ 54 & 4 & 6 & 31 & 50 & 9 & 0,81 & (0,65)\end{array}$

22. Ik vraag meer door over hoe de HAIO met (delen van) zichzelf als persoon (zijn opvattingen, gewoontes e.d.) omgaat.

23. Ik ben meer geïnteresseerd in de opvattingen van mijn $\mathrm{HAIO}$.

24. Ik heb minder moeite gekregen met het op tijd afronden van mijn consulten.

$1 \mathrm{~N}=$ aantal respondenten op deze vraag.

2 Score $=$ percentage respondenten met betreffende score. $1=$ geheel mee oneens/geheel in tegendeel; 2 = mee oneens/integendeel; 3 = noch oneens, noch eens; 4 = mee eens; 5 = geheel mee eens.

3 Veranderingsscore $=$ mate waarin de score van een respondent op deze vraag afwijkt van het midden. $0=$ in het midden (score 3 ); 1 = één punt buiten het midden (score 2 of 4); 2 = twee punten buiten het midden (score 1 of 5 ). Weergegeven worden gemiddelden met tussen haakjes de standaarddeviatie.

perimenteer meer met mijn handelen'. De uitzondering vormt de laatste stelling: 'Ik heb minder moeite gekregen met het op tijd afronden van mijn consulten'. Verschuiving naar rechts treedt hier even vaak op als verschuiving naar links. Daarbij is ook het percentage 'middenscorers' erg hoog, zodat de indruk ontstaat dat supervisie weinig met het op tijd afronden van consulten van doen heeft. Ook de stelling: 'Ik ben meer geïnteresseerd geraakt in de opvattingen van mijn HAIO' heeft een hoog percentage middenscorers.

\section{Mate van veranderingsscores}

In het bovenstaande is gerapporteerd over scores die HAIO's geven op stellingen met betrekking tot effecten van supervisieonderwijs. Per stelling is weergegeven in welke richting de verandering plaats vond en hoe sterk. Uit tabel 1 kunnen twee andere tabellen gehaald worden, waarin de zeven items met de hoogste veranderingsscores en de zeven items met de laagste veranderingsscores worden weergegeven (zie tabel 2 en tabel 3). 
Tabel 2. De 7 items met de hoogste veranderingsscores.

\begin{tabular}{|c|c|c|c|c|}
\hline $\begin{array}{l}\text { Rang- } \\
\text { nr. }\end{array}$ & Item & $\mathrm{N}$ & $\begin{array}{l}\text { Veranderings- } \\
\text { score }\end{array}$ & $\begin{array}{c}\text { Standaard- } \\
\text { deviatie }\end{array}$ \\
\hline 1. & $\begin{array}{l}\text { Ik experimenteer meer met mijn handelen (om daarmee beter } \\
\text { met probleemsituaties om te gaan). }\end{array}$ & 54 & 1,24 & 0,55 \\
\hline 2. & $\begin{array}{l}\text { Ik besteed meer aandacht aan hoe ik met (delen van) mijzelf } \\
\text { als persoon (mijn opvattingen, gewoontes, persoonlijkheid e.d.) } \\
\text { omga. }\end{array}$ & 52 & 1,23 & 0,61 \\
\hline 3. & $\begin{array}{l}\text { Ik ben meer gaan experimenteren met mijn gedrag bij } \\
\text { patiënten die ik moeilijk vond. }\end{array}$ & 54 & 1,19 & 0,62 \\
\hline 4. & Ik zie patiënten meer als uitdaging in plaats van als opgave. & 54 & 1,06 & 0,63 \\
\hline 5. & $\begin{array}{l}\text { Ik heb minder moeite gekregen met het stellen van mijn } \\
\text { grenzen. }\end{array}$ & 54 & 0,98 & 0,57 \\
\hline $6^{\mathrm{a}}$ & $\begin{array}{l}\text { Ik wijs de situatie en/of anderen in de situatie meer als } \\
\text { oorzaak aan (leg het probleem meer buiten mijzelf). }\end{array}$ & 54 & 0,87 & 0,65 \\
\hline $6^{\mathrm{b}}$. & $\begin{array}{l}\text { Ik handel minder vanuit het gevoel dat ik persoonlijk } \\
\text { aangevallen wordt. }\end{array}$ & 54 & 0,87 & 0,65 \\
\hline
\end{tabular}

Tabel 3. De 7 items met de laagste veranderingsscores.

\begin{tabular}{|c|c|c|c|c|}
\hline $\begin{array}{l}\text { Rang- } \\
\text { nr. }\end{array}$ & Item & $\mathrm{N}$ & $\begin{array}{l}\text { Veranderings- } \\
\text { score }\end{array}$ & $\begin{array}{c}\text { Standaard- } \\
\text { deviatie }\end{array}$ \\
\hline 1. & Ik ben meer geïnteresseerd in de opvattingen van mijn HAIO. & 52 & 0,48 & 0,64 \\
\hline 2. & $\begin{array}{l}\text { Ik heb minder moeite gekregen met het op tijd afronden van } \\
\text { mijn consulten. }\end{array}$ & 54 & 0,50 & 0,69 \\
\hline 3. & $\begin{array}{l}\text { Ik heb minder moeite met mijn neiging om bepaalde patiënten } \\
\text { te veroordelen. }\end{array}$ & 52 & 0,52 & 0,57 \\
\hline 4. & Ik heb minder moeite met mijn neiging om mijzelf te veroordelen. & 54 & 0,54 & 0,65 \\
\hline 5. & $\begin{array}{l}\text { Commentaar op mijn handelen interpreteer ik minder snel als } \\
\text { kritiek op mijn persoon. }\end{array}$ & 52 & 0,63 & 0,66 \\
\hline $6^{\mathrm{a}}$. & $\begin{array}{l}\text { Ik zie eerder hoe mijn gedrag geduid kan worden als een manier } \\
\text { om mij ergens uit te redden. }\end{array}$ & 51 & 0,69 & 0,65 \\
\hline $6^{\mathrm{b}}$. & $\begin{array}{l}\text { Ik heb minder moeite met het feit dat ik bepaalde patiënten } \\
\text { vaak weinig concreets te bieden heb. }\end{array}$ & 54 & 0,69 & 0,67 \\
\hline
\end{tabular}

In de tabellen 2 en 3 is onder meer te zien dat het experimenteren met het eigen handelen in het algemeen en bij moeilijke patiënten, het meer aandacht besteden aan hoe men met de eigenaardigheden van zichzelf als persoon omgaat en het zien van patiënten als uitdaging in plaats van als opgave punten zijn, waarop de HAIO's relatief veel verandering aange- ven. Items waarop weinig verandering is te zien zijn (we noemen de bovenste 5): interesse in de opvattingen van de praktijkopleider, het moeite hebben consulten op tijd af te ronden, de neiging om bepaalde patiënten en ook zichzelf te veroordelen en het interpreteren van commentaar op het eigen handelen als kritiek. 


\section{Discussie}

\section{Kracht en beperkingen van deze studie}

Onderzoek naar het effect van supervisie is nog niet veel gedaan. Dat houdt verband met het feit dat onduidelijk is wat nu de gewenste effecten van supervisie zijn en de vraag hoe die effecten objectief vastgesteld kunnen worden middels gedragsmetingen. ${ }^{5-6}$ De in dit onderzoek gebruikte methode is gekoppeld aan de evaluatie van de supervisie als onderwijsmethode, waarbij het er vooral om ging de waardering van de HAIO's vast te stellen voor diverse onderdelen van de methode. Daarvoor is het gebruik maken van een vragenlijst een goede en goed hanteerbare methode. Het spreekt vanzelf dat daarom ook gekozen is voor een subjectieve benadering van het meten van de effecten van supervisie, met alle voor- en nadelen van dien.

Het aantal beschikbare evaluatieformulieren en het responspercentage waren beperkt. Dit betekent dat de generaliseerbaarheid van de resultaten niet hoog genoemd kan worden. De hoeveelheid en de kwaliteit van de gegevens is echter voldoende om interessante inzichten op te leveren.

\section{Interpretatie van de resultaten}

HAIO's rapporteren veel veranderingen als gevolg van hun supervisie. Veel van de veranderingen gaan in de richting van zichzelf serieuzer nemen: zij worden zich er meer van bewust of problemen binnen of buiten henzelf liggen, zij gaan meer varen op hun eigen oordeel en ze gaan duidelijker hun eigen grenzen stellen. Ook geven ze aan minder te handelen vanuit het gevoel dat zij persoonlijk aangevallen worden. Het kan zeer wel zijn dat de sfeer van veiligheid die tijdens de supervisie gecreëerd wordt hieraan bijdraagt: tijdens de supervisiebijeenkomsten voelen de HAIO's aan den lijve wat het is om in een veilige omgeving over zichzelf en het werk te praten en er commentaar op te krijgen.

Eén van de weinige items waarop een verschuiving naar links optreedt, is het starten van een hobby. De vraag is hoe dit met de supervisie te maken heeft. Wordt de HAIO zich tijdens de supervisie misschien meer bewust van een gebrek aan tijd voor hobby's?

Uit de items met de hoogste veranderingsscores (tabel 2) kan men naar onze mening concluderen dat een onderliggende verandering heel waarschijnlijk te maken heeft met het zich steviger voelen ten opzichte van de omgeving. Bij de items die de laagste veranderingsscores laten zien zijn er twee die niet voor iedereen gelden, omdat de vooronderstelling waarop ze gebaseerd zijn niet voor iedere respondent opgaat: 'Ik heb minder moeite met mijn neiging om mijzelf te veroordelen' en 'Ik heb minder moeite met het feit dat ik bepaalde patiënten vaak weinig concreets te bieden heb'. In onze ogen hebben ze echter allemaal gemeenschappelijk dat ze verwijzen naar een opener en gemakkelijker omgaan met zichzelf en/of de omgeving, of dat nu patiënten zijn of de opleider.

Als mensen over zichzelf nadenken, en dat is grotendeels de kern van de supervisie, dan worden ze gestimuleerd een onderscheid te maken tussen zichzelf en hun bewustzijn. Het bewustzijn noemen we hier het 'ik-bewustzijn' dat het zelf waarneemt, beoordeelt en een relatie heeft met dat 'zelf' dat functioneert als HAIO. De ervaring hiervan noemen Alting von Geusau en Runia 7 de 'innerlijke ervaring'.

Een ander aspect van supervisie is de relatie die het 'zelf' dat functioneert (o.a. als HAIO), heeft met diens omgeving: de huisartsopleiding, de patiënten, de groep 
HAIO's met wie dat 'zelf' de opleiding volgt. Het ervaren van die relatie noemen Alting von Geusau en Runia de 'uiterlijke ervaring'.

In de supervisie gaat het dus om de relaties tussen drie elementen: het 'ik-bewustzijn' (dat het 'zelf' waarneemt), het 'zelf' (dat als instrument functioneert in diverse rollen) en de omgeving (in relatie met welke het 'zelf' functioneert). De indruk bestaat dat supervisie invloed heeft op zowel innerlijke als uiterlijke ervaring. Met betrekking tot de uiterlijke ervaring komt uit dit onderzoek dat de volgende veranderingen het sterkst zijn:

1. De oorzaak van probleemsituaties wordt meer bij zichzelf gelegd.

2. Men voelt zich steviger ten opzichte van de eisen, normen en verlangens van de omgeving.

Met betrekking tot de innerlijke ervaring komt uit dit onderzoek dat de sterkste verandering is:

3. De HAIO besteedt meer aandacht aan hoe zij of hij met zichzelf omgaat.

De resultaten van deze enquête geven echter aan dat het zich steviger ten opzichte van de omgeving voelen niet impliceert dat de HAIO daarmee opener en gemakkelijker met zichzelf en/of de omgeving omgaat. Voor zover er veranderingen in die richting optreden tijdens het supervisieonderwijs, zijn die veranderingen het minst sterk.

Wat dit betekent hangt af van hoe men tegen de doelen en gewenste effecten van supervisieonderwijs aankijkt. Ons idee is dat wie wil leren zichzelf beter als instrument te gebruiken altijd twee stappen moet zetten:

1. Het herkennen van eigen kenmerken: zelfinzicht en zelfbewustzijn vergroten.

2. Het accepteren van wat men herkent en erkent van zichzelf: door acceptatie van iets dat men van zichzelf herkent, door de juiste eigenschappen van zichzelf te zien en de waarde daarvan juist in te schatten, kan men het beste uit zichzelf halen.

Acceptatie is nodig om het ik-bewustzijn zo vrij mogelijk te maken het zelf als instrument te observeren en functioneel te sturen. Een voorbeeld.

HAIO $\mathrm{x}$ weet dat haar consulten te lang duren. Haar spreekuur loopt gemiddeld een half uur uit en haar opleider heeft daar opmerkingen over gemaakt. In de supervisie blijkt dat zij graag aardig gevonden wordt door de patiënten. Haar waardering van zichzelf als huisarts hangt dan ook sterk af van de tevredenheid die zij van de patiënten oogst. Ditzelfde werkt in haar relatie met haar opleider, waardoor zij het uitlopen van haar spreekuur extra als probleem ervaart. In de supervisie pikt zij ook op dat je eigen doelen en je eigen tijdsindeling even belangrijk zijn als die van de patiënt en dat een ontevreden patiënt niet betekent dat je een slechte dokter bent. Ze is zichzelf dus bewust geworden van het feit dat zij aardig gevonden wil worden en ook dat zij zichzelf ondergeschikt maakt aan het aardig gevonden worden. Wat rest is het gevoel dat het streven om aardig gevonden te worden niet functioneel is.

Zonder te werken aan acceptatie van wat ze van zichzelf nu bewust is geworden, gaat HAIO x terug naar de praktijk. Ze wordt wat minder aardig tegenover patiënten en komt meer voor zichzelf op. Het lukt haar om minder tijd te verliezen. Maar het kost haar veel moeite. Wat voegt acceptatie toe? Acceptatie houdt in dat HAIO $x$ erkent dat zij die neiging heeft om vooral aardig gevonden te worden door patiënten en niet probeert die neiging meteen weg te drukken. Ze kan proberen de neiging functioneel te maken, de voor- 
delen ervan uit te buiten en de nadelen ervan zo klein mogelijk te maken. Voordelen: de patiënten gaan je vertrouwen, je krijgt waardering, en dergelijke. Nadelen: je loopt over je eigen behoeftes heen. Doordat zij dit onderdeel van zichzelf accepteert, ervaart zij hoe het is als iets van jezelf geaccepteerd wordt. Zij durft nu ook meer naar andere eigenschappen van zichzelf te kijken zonder direct bang te zijn dat ze niet gewaardeerd wordt. In de praktijk kan ze nu gemakkelijker zowel aardig zijn tegen patiënten als consulten beter op tijd afsluiten zonder erg gespannen te zijn als het een keer niet lukt.

Zou dit voorbeeld de werkelijke gang van zaken tijdens het supervisieonderwijs weergeven, dan kan dat betekenen dat tijdens het supervisieonderwijs minder bereikt wordt aan acceptatie dan aan bewustwording. Immers, de HAIO's geven aan dat zij relatief weinig verandering ervaren in de moeite die zij hebben om hun consulten op tijd af te ronden. Het geheel van het lijstje van items met de minste verandering kan in die richting wijzen. Als het inderdaad aangeeft dat supervisieonderwijs weinig effect heeft op het opener en gemakkelijker omgaan met de omgeving en met zichzelf, dan kan dat twee dingen betekenen: (1) er wordt relatief weinig aandacht aan acceptatie gegeven of (2) acceptatie is een moeilijker te bereiken stap in het proces dan bewustwording en zelfinzicht.

In de doelstellingen van supervisieonderwijs wordt acceptatie niet expliciet genoemd, hoewel aan acceptatie in de supervisienota van 2002 aan de HAIO's van de Huisartsopleiding VUMC wel aandacht besteed wordt. ${ }^{8}$ Wij pleiten ervoor dat er expliciet aan acceptatie gewerkt wordt tijdens het supervisieonderwijs.

Een tweede opmerking betreft het onderzoek zelf. Pogingen om de items van de vragenlijst te ordenen naar de indeling van Alting von Geusau en Runia in items die effecten op innerlijke en items die effecten op uiterlijke ervaring weergeven, mislukten vrijwel allemaal. In vrijwel alle items is zowel van innerlijke als van uiterlijke ervaring iets weergegeven. Vanuit de resultaten van dit onderzoek zijn de volgende invalshoeken te herkennen van waaruit men effectitems kan formuleren naast de invalshoek, die de doelstellingen van het supervisieonderwijs reeds bieden:

1. De mate waarin de HAIO grotere stevigheid ervaart, zichzelf minder ondergeschikt acht aan zijn of haar omgeving.

2. De mate waarin de HAIO (de eigenschappen, gewoontes e.d. van) zichzelf als instrument, werkend en lerend in de praktijk accepteert.

3. De mate, waarin de HAIO opener, nieuwsgieriger wordt ten opzichte van zichzelf en haar of zijn omgeving.

Dit artikel is een eerste rapportage over de effecten van supervisieonderwijs. We gaan verder met dataverzameling totdat we voldoende respons hebben om meer geavanceerde methoden van datareductie toe te passen, zoals factoranalyse.

\section{Literatuur}

1. Schmitz MBG, et al. Nota Supervisie Huisartsen Opleiding Vrije Universiteit 1999.

2. Brenninkmeijer WJM, Rossum MM van, Mokkink HGA. De evaluatie van supervisie voor HAIO's. Huisarts en Wetenschap 1999;42(9):4025.

3. Kolb DA. Experiential learning. Experience as a source of learning and development. Englewood Cliff: Prentice Hall; 1984.

4. Moosdijk-Smeelen J van de. De betekenis die supervisie heeft als opleidingsmethode voor de huisarts in opleiding [dissertatie]. Nijmegen; 1992.

5. Schmitz MBG, Merkies QL. Supervisie in het kader van de beroepsopleiding tot huisarts. Amsterdam: Vrije Universiteit; 1990.

6. Brenninkmeijer W, Grol R, Lieshout V van. Evaluatie van de supervisie en persoonsgerichte training. Huisarts en Wetenschap 1986;29:319-21. 
7. Alting von Geusau WAM, Runia EH. De prijs van het aardig zijn: supervisie als nascholingsmethode voor huisartsen. Utrecht: Nederlands Huisartsen Genootschap; 1991.

8. Mannens M, Raths A, Schmitz MB, Feijen W. Supervisienota HAIO's. Amsterdam: Huisartsopleiding VU Medisch Centrum; maart 2002. p. 10.
De auteurs:

Dr. G. Locher is gedragswetenschappelijk medewerker en verbonden aan de Huisartsopleiding van het VUMC. Dr. A.H. Blankenstein is als huisarts en onderzoeker verbonden aan de Onderzoeksgroep Huisartsgeneeskunde, EMGO-Instituut, VUMC.

\author{
Correspondentieadres: \\ Dr. Gerrit Locher, Huisartsopleiding VUMC, Overschie- \\ straat 180, 1062 XK Amsterdam, tel: 020-4449346, g.lo- \\ cher@vumc.nl.
}

\section{Summary}

Introduction: In Year 3 of the vocational training programme for general practice, groups of three GP trainees discuss their experiences in general practice with their supervisor in ten two-hour sessions aimed at stimulating trainees to reflect on their experiences, increase their self-knowledge, draw conclusions from their experiences and change their conduct accordingly, and take responsibility for their own learning processes. This paper evaluates the trainees' selfreported effects of the supervision sessions. The study question was: which strong and weak effects result from the supervision sessions?

Methods: Between 1999 and 2001, GP trainees at the Vrije Universiteit (n=108) were asked to complete a questionnaire after their supervision sessions. The questionnaire asked the trainees to indicate agreement with 24 possible effects of the sessions on a five-point Likert scale ( $1=$ fully disagree; $5=$ fully agree). Item scores 1 and 5 were regarded as representing a strong effect (score 2), item scores 2 and 4 were seen as weak effects (effect score 1), and item score 3 was regarded as no effect.

Results: Fifty-four trainees responded (50\%). Strong effects were reported for "increase in experimenting with my behaviours in practice" and for self-management. The weakest effects were those for increased interest in the GP trainer's views, problems with time-management in consultations and a tendency to be judgemental about patients.

Discussion: Supervision appears to raise GP trainees' awareness of their personal characteristics. However, trainees do not seem to achieve acceptance of these characteristics. Self-acceptance is proposed as an explicit aim for supervision courses. In addition, new wordings for effect items are proposed. (Locher G, Blankenstein AH. The effects of supervision in vocational training for general practice. Dutch Journal of Medical Education 2004;23(3):143-152.) 